Pacific Journal of Mathematics

GROUPS WITH FREE NONABELIAN SUBGROUPS

Robert Ko and MYron L aURa ANe Krom 


\title{
GROUPS WITH FREE NONABELIAN SUBGROUPS
}

\author{
Melven Krom and Myren Krom
}

Conditions are given which characterize the class of groups with free nonabelian subgroups. It is also shown that a generalization of the conditions characterize the class of nonamenable groups. Neither of these two (possibly identical) classes of groups is the class of models of any finite set of first-order axioms.

THEOREM 1. A group $G$ has a free nonabelian subgroup if and only if there are two subsets $M, N$ of $G$ and two elements $a, b$ of $G$ such that:

$$
\begin{gathered}
M \cup N_{-}=G \\
a M \cap b N=\varnothing \\
a M \cup b N \subset M \cap N .
\end{gathered}
$$

Lemma. Let $X$ be a set of elements of a group $G$ such that if $x \in X$ then $x^{-1} \notin X$ and let $Y$ be the set of $x$ and $x^{-1}$ for $x \in X$. Suppose that to each $y \in Y$ is associated a subset $U_{y}$ of $G$ such that $y \in U_{y}, 1 \notin U_{y}$, and for all $y, z \in Y$ such that $y z \neq 1$, we have $y U_{z} \subset U_{y}$. Then the subgroup generated by $X$ is free.

Proof of the lemma. By induction on length we show that any reduced word of positive length in elements of $X$ is in the union of the $U_{y}$ and thus it is not the identity.

Proof of Theorem 1. Assume $G$ has a free subgroup $H$ on two free generators $a, b$ and let $R$ be a set consisting of one element from each right coset of $H$ in $G$ such that $1 \in R$. Let $M$ be the set of all elements $w r$ for $r \in R$ and $w$ a reduced word in $H$ not beginning with $a^{-1}$ and let $N$ be the set of all elements $z r$ for $r \in R$ and $z$ a reduced word in $H$ not beginning with $b^{-1}$. Then the conditions of the theorem are satisfied.

Conversely, suppose that the conditions of the theorem are satisfied for subsets $M, N$ and elements $a, b$. First we observe that we may assume

$$
a^{-1} \notin M \text { and } b^{-1} \notin N .
$$

For example, if $a^{-1} \in M$, then $b^{-1} \notin N$ by (2) and we replace $a$ with $b a$ and $N$ with $N-a M$. The resulting subsets $M, N-a M$ and cor- 
responding elements $b a, b$ satisfy (4) and the three conditions of Theorem 1. (The proof, which we omit, is straightforward. To establish condition (3) for the replacement sets we use $b a M \subset b N$, which is a consequence of (3) for the given sets $M, N$.) Next we observe that we may assume

$$
1 \in M \cap N .
$$

For example, if $1 \notin M$ then $1 \in N$ by (1). Also by (1) and (3) either $a \in M$ or $b a \in M$ and by (3) $M \subset a^{-1} M$ and $M \subset a^{-1} b^{-1} M$. If $a \in M$, replace $a$ with $a^{2}$ and $M$ with $a^{-1} M$ and if $b a \in M$, replace $a$ with $a b a$ and $M$ with $a^{-1} b^{-1} M$. Under these replacements, or similar ones involving $N$ if $1 \notin N$, condition (4) remains valid. The conditions in the lemma are satisfied with $X=\{a, b\}, U_{a}=a M, U_{b}=b N, U_{a^{-1}}=$ $a^{-1}(G-a M)$, and $U_{b^{-1}}=b^{-1}(G-b N)$. We conclude that $G$ has a free nonabelian subgroup.

A problem posed in 1957 (cf. [1, p. 520]) is to determine whether the class of groups with free nonabelian subgroups is identical with the class of nonamenable groups. Evidence suggests that the two classes coincide (cf. [2, p. 12] and [3, p. 9]). By Theorem 1 the two classes do coincide if and only if the finite sequences mentioned in the following theorem may be limited to two terms.

THEOREM 2. A group $G$ is not amenable if and only if there is a finite sequence $\left(a_{1}, M_{1}\right),\left(a_{2}, M_{2}\right), \ldots,\left(a_{n}, M_{n}\right)$ of (not necessarily distinct) ordered pairs where $a_{i} \in G$ and $M_{i} \subset G$ for $i=1, \cdots, n$, and such that for every $x \in G$ the number of terms with $x \in M_{i}$ is strictly greater than the number of terms with $x \in a_{i} M_{i}$.

Proof. This theorem is a consequence of a theorem by Dixmier (cf. [3, p. 4]). The conditions in Dixmier's theorem are equivalent to the same conditions with the functions restricted to characteristic functions.

A class of groups is a generalized elementary class in case it is the class of models of a (possibly infinite) set of first-order sentences (cf. [5, p. 92, problem 2]). An easy application of the compactness theorem (cf. 5, p. 70]) shows that any generalized elementary class of groups that contains all finite groups also contains an extension of every residually finite group. Also every free group is residually finite (cf. [4, p. 116]), so every free group has an extension in any generalized elementary class that contains all finite groups. It follows that neither the class of groups with free nonabelian subgroups nor the class of nonamenable groups is the class of models of a finite set of first-order axioms because in each case the complementary class is not a generalized elementary class. 


\section{BIBLIOGRAPHY}

1. M. M. Day, Amenable semigroups, Illinois J. Math. 1 (1957), 509-544.

2. - Semigroups and Amenability, Proceedings of a Symposium on Semigroups, Detroit, Michigan, Academic Press, New York, 1969.

3. F. P. Greenleaf, Invariant Means on Topological Groups and Their Applications, Van Nostrand Company, New York, 1969.

4. W. Magnus, A. Karrass, and D. Solitar, Combinatorial Group Theory, Interscience Publishers, New York, 1966.

5. J. R. Shoenfield, Mathematical Logic, Addison-Wesley Publishing Company, Menlo Park, 1967.

Received January 21, 1970

UNiversity of CALIFornia, Davis

Sacramento State College 



\section{PACIFIC JOURNAL OF MATHEMATICS}

\section{EDITORS}

\author{
H. SAMELSON \\ Stanford University \\ Stanford, California 94305

\section{Richard Pierce} \\ University of Washington \\ Seattle, Washington 98105
}

J. DugundJI

Department of Mathematics

University of Southern California

Los Angeles, California 90007

RichaRd ARENS

University of California

Los Angeles, California 90024

\section{ASSOCIATE EDITORS}
E. F. BECKENBACH
B. H. NeUMANN
F. WOLE
K. YoshidA

\section{SUPPORTING INSTITUTIONS}

\author{
UNIVERSITY OF BRITISH COLUMBIA \\ CALIFORNIA INSTITUTE OF TECHNOLOGY \\ UNIVERSITY OF CALIFORNIA \\ MONTANA STATE UNIVERSITY \\ UNIVERSITY OF NEVADA \\ NEW MEXICO STATE UNIVERSITY \\ OREGON STATE UNIVERSITY \\ UNIVERSITY OF OREGON \\ OSAKA UNIVERSITY \\ UNIVERSITY OF SOUTHERN CALIFORNIA
}

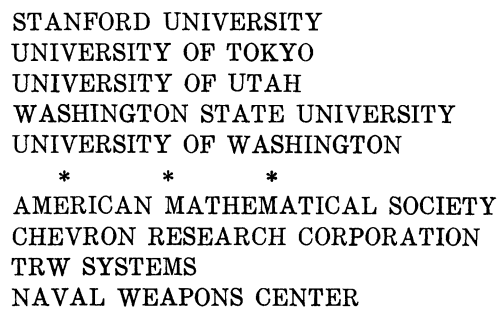

The Supporting Institutions listed above contribute to the cost of publication of this Journal, but they are not owners or publishers and have no responsibility for its content or policies.

Mathematical papers intended for publication in the Pacific Journal of Mathematics should be in typed form or offset-reproduced, (not dittoed), double spaced with large margins. Underline Greek letters in red, German in green, and script in blue. The first paragraph or two must be capable of being used separately as a synopsis of the entire paper. The editorial "we" must not be used in the synopsis, and items of the bibliography should not be cited there unless absolutely necessary, in which case they must be identified by author and Journal, rather than by item number. Manuscripts, in duplicate if possible, may be sent to any one of the four editors. Please classify according to the scheme of Math. Rev. Index to Vol. 39. All other communications to the editors should be addressed to the managing editor, Richard Arens, University of California, Los Angeles, California, 90024.

50 reprints are provided free for each article; additional copies may be obtained at cost in multiples of 50 .

The Pacific Journal of Mathematics is published monthly. Effective with Volume 16 the price per volume (3 numbers) is $\$ 8.00$; single issues, $\$ 3.00$. Special price for current issues to individual faculty members of supporting institutions and to individual members of the American Mathematical Society: $\$ 4.00$ per volume; single issues $\$ 1.50$. Back numbers are available.

Subscriptions, orders for back numbers, and changes of address should be sent to Pacific Journal of Mathematics, 103 Highland Boulevard, Berkeley, California, 94708.

PUBLISHED BY PACIFIC JOURNAL OF MATHEMATICS, A NON-PROFIT CORPORATION

Printed at Kokusai Bunken Insatsusha (International Academic Printing Co., Ltd.), 7-17, Fuj̣imi 2-chome, Chiyoda-ku, Tokyo, Japan. 


\section{Pacific Journal of Mathematics}

\section{Vol. 35, No. $2 \quad$ October, 1970}

Valentin Danilovich Belousov and Palaniappan L. Kannappan, Generalized Bol functional equation .................................... 259

Charles Morgan Biles, Gelfand and Wallman-type compactifications ........... 267

Louis Harvey Blake, A generalization of martingales and two consequent convergence theorems .................................... 279

Dennis K. Burke, On p-spaces and $w \Delta$-spaces..................... 285

John Ben Butler, Jr., Almost smooth perturbations of self-adjoint operators . . . . . . 297

Michael James Cambern, Isomorphisms of $C_{0}(Y)$ onto $C(X) \ldots \ldots \ldots \ldots \ldots . \ldots 307$

David Edwin Cook, A conditionally compact point set with noncompact closure ... 313

Timothy Edwin Cramer, Countable Boolean algebras as subalgebras and homomorphs .........................................

John R. Edwards and Stanley G. Wayment, A v-integral representation for linear operators on spaces of continuous functions with values in topological vector spaces.............................................

Mary Rodriguez Embry, Similarities involving normal operators on Hilbert

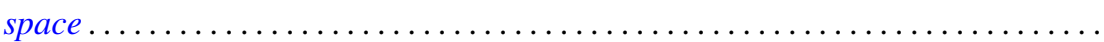

Lynn Harry Erbe, Oscillation theorems for second order linear differential

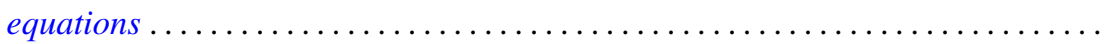

William James Firey, Local behaviour of area functions of convex bodies .......... Joe Wayne Fisher, The primary decomposition theory for modules ..............

Gerald Seymour Garfinkel, Generic splitting algebras for Pic ..................

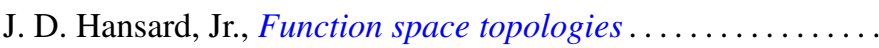

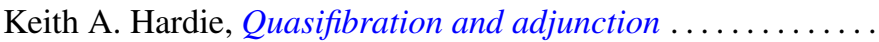

G. Hochschild, Coverings of pro-affine algebraic groups ...........

Gerald L. Itzkowitz, On nets of contractive maps in uniform spaces ..

381

389

399

417

Melven Robert Krom and Myren Laurance Krom, Groups with free nonabelian subgroups....................................

James Robert Kuttler, Upper and lower bounds for eigenvalues by finite differences ......................................

Dany Leviatan, A new approach to representation theory for convolution transforms . . .

Richard Beech Mansfield, Perfect subsets of definable sets of real numbers ...

Brenda MacGibbon, A necessary and sufficient condition for the embedding of a

Lindelof space in a Hausdorff $\mathscr{H} \sigma$ space ..................

David G. Mead and B. D. McLemore, Ritt's question on the Wronskian ....

Edward Yoshio Mikami, Focal points in a control problem .....

Paul G. Miller, Characterizing the distributions of three independent n-dimensional random variables, $X_{1}, X_{2}, X_{3}$, having analytic characteristic functions by the joint distribution of $\left(X_{1}+X_{3}, X_{2}+X_{3}\right)$. . .

P. Rosenthal, On the Bergman integral operator for an elliptic partial differential equation with a singular coefficient....

Douglas B. Smith, On the number of finitely generated $O$-group 